\title{
NEWS LETTFR
}

\section{Manitoba Division}

Dr. A. W. (Tony) Natsuk of the Department of Anaesthesia at the Misericordia General Hospital was elected to the office of President of the Medical Staff. At the same time the department was granted the status of a separate and independent department in that hospital.

On the recommendation of the sub-department of anaesthesia at the University of Manitoba, a Mortality Study Committee was inaugurated by the Manitoba Medical Association. Doctor Max Minuck was appointed as its first chairman. The purpose of the committee is to study all deaths in the province of Manitoba associated with anaesthesia and surgery.

Dr. G. Semelka of the Department of Anaesthesia, St. Bonifacle General Hospital, attended the First European ${ }_{\bullet}$ Congress of Anaesthetists. He spoke on "Recovery Room and Post Surgery Wards at the St. Boniface General Hospital," and also took part in a symposium, "The Influence of the Doctor-Patient Relationship." While in Europe, Dr. Semelka also attended the International Congress of Physiology at Leyden, West Germany.

\section{Ontario Division}

Dr. Shirley Fleming of the Department of Anaesthesia, University of Toronto, is Professor of Anaesthesia at Lagos University Medical School in Nigeria with the responsibility of organizing the department in this new school. Dr. Earl Russell of the Department of Anaesthesia of Queen's University is also in Lagos as Dr. Fleming's Assistant in the Department.

Dr. A. C. Webster has left his anaesthetic practice in Brantford to return to the University of Leeds as Lecturer in the Department of Anaesthesia. 